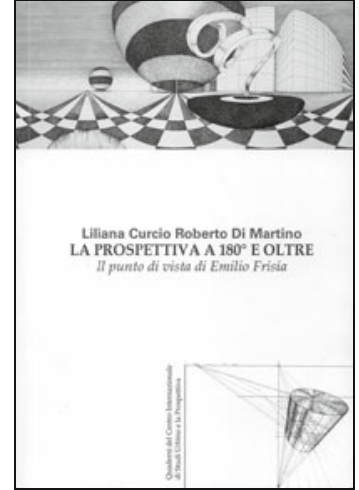

Keywords: Liliana Curcio, Roberto Di Martino, perspective, Emilio Frisia
Book Review

\section{Liliana Curcio and Roberto Di Martino}

\section{La prospettiva a $180^{\circ}$ e oltre. Il punto di vista di Emilio Frisia}

Quaderni del Centro Internazionale Urbino e la Prospettiva 4

Urbino: Centro Internazionale di Studi "Urbino e la

prospettiva”, 2009

Reviewed by Sylvie Duvernoy

Via Benozzo Gozzoli, 26

50124 Florence ITALY

syld@kimwilliamsbooks.com

Emilio Frisia (1924-2004), an Italian professional photographer, was the son of Donato Frisia, a painter acquainted with Modigliani and Guttuso. Frisia taught drawing and descriptive geometry at the Istituto Statale d'Arte of Monza, near Milan, for many years. His artistic talent, coupled with his scientific skills, made him an extraordinary teacher. His passion for all kinds of graphic art, whether achieved with mechanical tools (photographic device or computer technology) or manual means (pencils, watercolour, etc.) led him to investigate in depth all the opportunities offered by the combination of modern and traditional graphic tools, in order to produce fantastic views of imaginary spaces.

Authors Liliana Curcio and Roberto di Martino, who are both teachers at the same school where Frisia used to work, present the results of his research. The authors are wellknown to the readers of the Nexus Network Journal and followers of the Nexus conference; they organized the exhibits of student work that accompanied Nexus 2000 in Ferrara and Nexus 2006 in Genoa.

The artworks by Emilio Frisia published in this book are all two-dimensional printed images, rendered by hand, representing unnatural three-dimensional views of virtual outdoor or indoor spaces, to which the author gives poetic titles such as "Staircase on the seashore, climbing towards the unknown" or "Solitude of a couple in the museum".

In order to produce his three-dimensional views Frisia makes use of all kinds of geometric projection: linear perspective, axonometric projection, cartographic projections, and more. Sometimes more than one step is necessary to construct the final view. Furthermore, effects of reflections on mirroring surfaces, and/or effects of various light refractions are added to the imaginary space to evoke some particular feelings in the viewer; this is the case, for instance, of the picture entitled "nightmares in a glass cube".

A series of images entitled "Una città ideale - an ideal city", dedicated to Piero della Francesca, show a urban space which is successively represented thanks to different kinds of map projections, such as stereographic projection, Mercator projection, SansonFlamsteed projection, etc. 


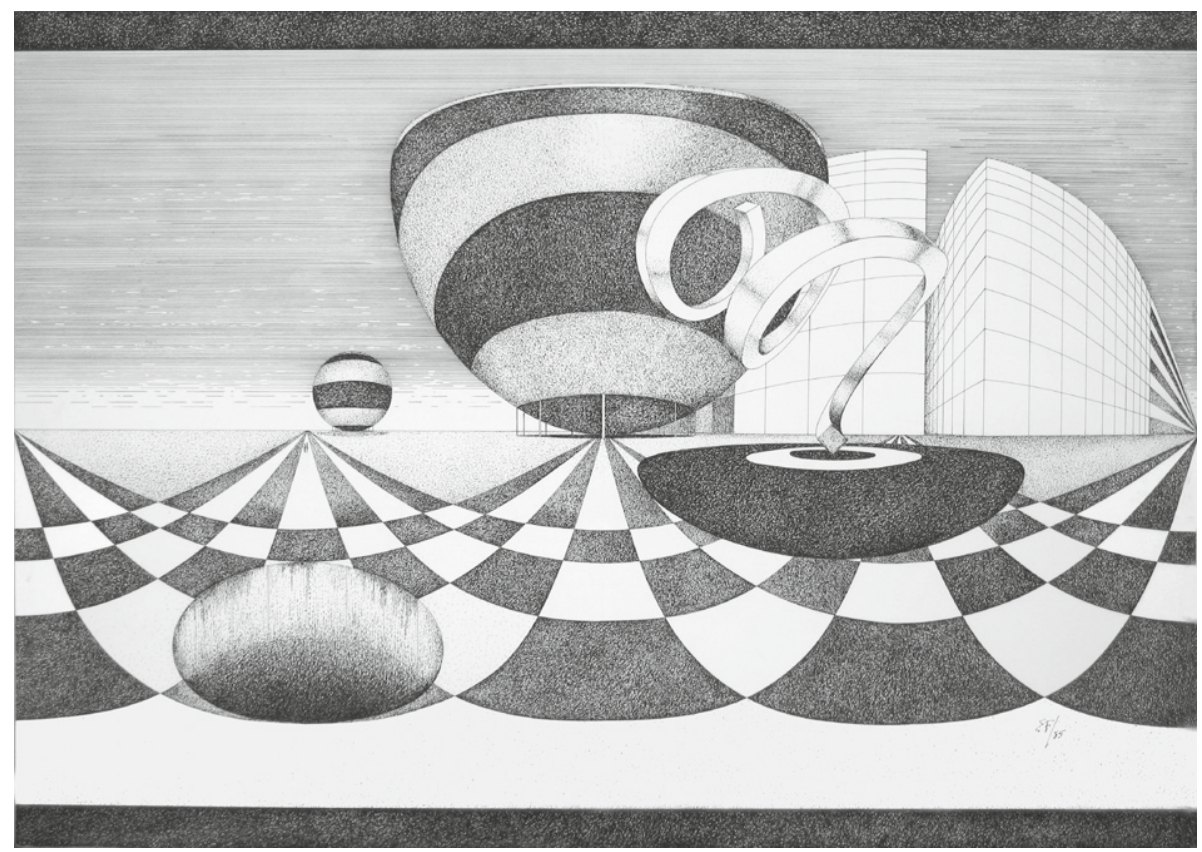

Even though Liliana Curcio and Roberto di Martino did not intend the book as a textbook meant to explain how to build sophisticated three-dimensional views, it clearly points out the relationships existing between the major conic projections, such as linear perspective, anamorphosis and cartography, which traditional teaching does not always sufficiently explain. The sheer beauty of the illustrations is enough to explain why modern students should continue, even today, to study and learn the techniques of map projection. In fact, cartography is still taught to architecture students, at least in Italy, although the drawing of maps has nowadays become a highly specialized task, evolving together with modern computer and geospatial technologies, which contemporary architects are not expected to master. The didactic purpose of studying map projection lies in the observation of the close, reciprocal connection that exists between representation techniques and final goals. Moreover, the possible applications of techniques of map projection and spherical perspective are not restricted to cartography, but can be used to construct to views of complex curved architectural forms, for which the usual methods of orthographic projection (section and/or elevation), or of linear perspective, do not result in images that are sufficiently expressive and communicative.

Emilio Frisia is obviously not an isolated exception in the wide world of drawing teachers. Many other talented artists are currently teaching geometry and drawing to art and architecture students around the world, and many of these produce valuable works of art. But the collection of Frisia's beautiful drawings presented here show that even artwork produced in the realm of didactic activity and didactic experimentation may deserve to be published, simply for the sake of being seen and admired.

\section{About the reviewer}

Sylvie Duvernoy is Book Review Editor of the Nexus Network Journal. 